\title{
Removal of styrene from air by photocatalytic process of Zeolite Socony Mobil-5 coated with zinc oxide nanoparticles
}

\author{
Shojaee-Farah Abady H, MSc ${ }^{1}$, Fouladi Dehaghi B, $\mathrm{PhD}^{2}$, Irvani H, MSc${ }^{3}$, Vahidi A, $\mathrm{MSc}^{4}$, \\ Nakhaei Pour M, MSc ${ }^{5^{*}}$
}

1- MSc in Occupational Health Engineering, Dept. of Occupational Health Engineering, Faculty of Medical Sciences, Tarbiat Modares University, Tehran, Iran. 2- Assistant Prof. of Occupational Health Engineering, Dept. of Occupational Health, Faculty of Health, Ahvaz Jundishapur University of Medical Sciences, Ahvaz, Iran. 3- MSc in Occupational Health Engineering, Dept. of Occupational Health Engineering, Faculty of Health, Shahid Beheshti University of Medical Sciences, Tehran, Iran. 4- MSc in Health, Safety and Environment, Faculty of Health, Safety, and Environment, Shahid Beheshti University of Medical Sciences, Tehran, Iran. 5- MSc in Occupational Health Engineering, Dept. of Occupational Health, Faculty of Health, Ahvaz Jundishapur University of Medical Sciences, Ahvaz, Iran.

Abstract

Received: June 2017, Accepted: October 2017

Background: Volatile organic compounds (VOC) are considered as major environmental contaminants that have a harmful effect on human and ecosystem health, so much effort has been focused on their removal. The aim of this study was to investigate the removal efficiency of styrene by Zeolite Socony Mobil-5 (ZSM-5) after immobilization of nanoparticles of zinc oxide ( $\mathrm{ZnO})$ on it.

Materials and Methods: In this experimental study and in order to produce styrene, clean dry air with a constant flow rate of $1 \mathrm{l} /$ minute was pumped into an impinger containing styrene solution which resulted in the evaporation of styrene. Produced vapors entered into the mixing chamber to be mixed with clean air. Produced styrene with certain concentrations of 20, 100 and $300 \mathrm{ppm}$ was sent to a reactor containing $\mathrm{ZSM}-5 / \mathrm{ZnO}$ bed to investigate the effectiveness of the bed in the elimination of styrene.

Results: This study focused on removal of styrene using $\mathrm{ZnO}$ nanoparticles stabilized on ZSM-5 Zeolite. The highest removal efficiency of styrene was $47.5 \%$ in concentrations of $20 \mathrm{ppm}$. For concentrations of 100 and $300 \mathrm{ppm}$, the efficiency was $22 \%$ and $12.5 \%$, respectively.

Conclusions: Both adsorption and catalytic mechanisms can be effective in removal of pollutants in different conditions. Findings related to adsorption and removal of styrene also showed that coating $\mathrm{ZnO}$ nanoparticles on zeolite absorbent in presence of ultraviolet (UV) has increased the removal efficiency.

Keywords: Styrene, Zinc Oxide, ZSM-5, Air

\section{Introduction}

As volatile organic compounds (VOC) are considered as major environmental contaminants with a harmful effect on human and ecosystem health, much effort has been focused on their removal. For example, styrene is used extensively in the production of plastics and rubbers and many workers are exposed to harmful gaseous styrene in the workplace. Continuous exposure to small quantities of styrene has shown to have neurotoxic, hematological, cytogenetic and carcinogenic effects in humans $(1,2)$. Thus, the threshold limit value recommended by the American Conference of Governmental Industrial Hygienists is only 20 ppm (1-3).

According to what was mentioned, removing these pollutants from air and outlet air of styrene generator has considerable importance. There are several ways to reduce or eliminate polystyrene. In recent years photocatalytic oxidation in the gas phase has attracted much

\footnotetext{
* Corresponding author: Mojtaba Nakhaei pour, Dept. of Occupational Health, Faculty of Health, Ahvaz Jundishapur University of Medical Sciences, Ahvaz, Iran.

E-mail: nakhaei.m@ajums.ac.ir
} 
attention. Photocatalyst generally lowers the activation energy of the reaction and accelerates the breaking of organic substance molecules bond, and consequently increases the efficiency of the removal process (4). In the case of photocatalysts, titanium dioxide $\left(\mathrm{TiO}_{2}\right)$ with no doubt has been the most widely studied material $(5,6)$. However, zinc oxide $(\mathrm{ZnO})$ has shown similar or sometimes even better photocatalytic activity than $\mathrm{TiO}_{2}$ and considered as a very promising alternative. Moreover, $\mathrm{ZnO}$ is cheap, has low toxicity and can be produced by a variety of methods (7, 8). Many studies have proved the complete destruction and mineralization of environmental pollution by $\mathrm{ZnO}$ nanoparticles $(9,10)$. One of the outstanding features of $\mathrm{ZnO}$ is its wide band gap [3.37 electron volts $(\mathrm{eV})]$ and large excitonic binding energy of $60 \mathrm{MeV}$ at room temperature. These characteristics have turned $\mathrm{ZnO}$ to a promising material in electronics, solar cells, lightemitting devices, gas sensors, and photocatalysts (11-16).

The most important restriction of the photocatalytic process is a low surface area causing efficiency reduction. Today this limitation is overcome by applying foundation to the high surface area and increasing the retention time. Thus, stabilization of $\mathrm{ZnO}$ nanoparticles onto the adsorbent will increase the efficiency and optical damage due to adsorption of organic molecules and enhancement of concentration and retention time of organic matters around the catalyst particles (17). One of the adsorbents that have attracted a lot of attention, as the foundation for the catalyst, is zeolites. Zeolite is a Greek word meaning boiling stones. So far, more than 50 species of natural zeolites are known that clinoptilolite, hollandite, laumontite, modernize and phillipsite are the most important ones. In addition, more than a hundred species have been synthesized in the laboratory, among them, A, X, Y and Zeolite Socony Mobil-5 (ZSM-5) are widely used synthetic zeolites. They are crystalline and linked in all three directions to create a three- dimensional structure that gives them a certain chemical and physical resistance. Zeolites with a broad surface could potentially be used for pollutant adsorption and catalytic reactions. Its active surface can accelerate the decay and destruction of large molecules. Zeolites have the ability to lose and gain reversible water and exchange some of the constituent elements without any major change in their own structure $(18,19)$. ZSM-5 synthetic zeolite is part of pentasil family and has mordenite framework inverted (MFI) structure that consists of five rings. This kind of zeolite has high silica levels $(\mathrm{Si} / \mathrm{Al}>5)$ which makes it more non-polar. According to the features that were mentioned for zeolites, this adsorbent is known as one of the best foundations for nanoparticles, including $\mathrm{ZnO}$. Researches have shown that if nanoparticles (semiconductors or metals) enter into the pores of porous materials, the newly formed material will undoubtedly have some of the unique properties of nanoparticles and porous material simultaneously (20). The results of the study by Mohamed et al. indicated that photodegradation of ethylenediaminetetraacetic acid (EDTA) by impregnation method is much better than that of solid-solid interaction method (21).

Considering the destructive effects of VOC compounds on human and environment, reducing and controlling these substances seems to be necessary. Therefore, the main purpose of this study was to determine the efficiency of $\mathrm{ZnO}$ nanoparticles coated on ZSM-5 for the removal of styrene vapor from the polluted air.

\section{Material and Methods}

ZSM-5 zeolite used in this investigation had a particle size of 0.5 to $1 \mathrm{~mm}$ and $\mathrm{Si} / \mathrm{Al}$ ratio of 40. It was made in China and purchased from Iran zeolite store. Styrene (purged more than 99.98) and $\mathrm{ZnO}$ nanoparticles with a size of 10 to $20 \mathrm{~nm}$ (USA) was respectively purchased from Merck (Germany) and Iranians Nanomaterials Company. 
X-ray diffraction was collected by X-PERT PRO MPD X-ray powder diffractometer operated at $35 \mathrm{kV}$ and $25 \mathrm{~mA}$, using $\mathrm{Cu} \mathrm{K}$ radiation (lambda $=1.5418 \hat{\mathrm{A}}$ ). The intensity data were collected in a 2 range from $1^{\circ}$ to 80 $\circ$. The surface morphology of the adsorbents was observed by employing scanning electron microscope (SEM). The Brunauer, Emmett and Teller (BET) specific surface area of the samples was measured by $\mathrm{N} 2$ adsorptiondesorption isotherms at $77 \mathrm{~K}$ using Quantachrome ChemBET instrument (USA).

This study was carried out by an experimental set up for generating the known styrene vapors concentrations at 20, 100 and $300 \mathrm{ppm}$. A simple schematic of the system used in this study is shown in figure 1 . In order to provide inlet air, a pump with $51 \mathrm{~W}$ power and pressure of $11.147 \mathrm{mmHg}$ (manufactured by Hitachi Ltd) was used. The container with activated carbon and silica gel bed was also used to remove inlet air humidity and volatile impurities. Then, the inlet air entered the humidification and concentration system. In order to produce styrene, clean dry air with a constant flow rate of 11 per minute was pumped into an impinger containing styrene solution which resulted in evaporation of styrene. Produced vapors entered into the mixing chamber. After mixing with humidity and clean air, produced styrene with certain concentrations was sent to a reactor containing $\mathrm{ZSM}-5 / \mathrm{ZnO}$ bed. The reactor used in this study was designed for ZSM-5 zeolite with a particle size of 0.5 to $1 \mathrm{~mm}$. This cylindrical reactor was made of quartz glass to allow passage of ultraviolet (UV) radiation, and had $28 \mathrm{~cm}$ length, $22 \mathrm{~mm}$ diameter and $2 \mathrm{~mm}$ thickness. Input and output of reactor were in the opposite direction within $2 \mathrm{~cm}$ of cylinder ends, so that an 8-W UV lamp could be placed in the core of the reactor and three $6-\mathrm{W}$ bulbs on the outside of the reactor. The distance between the UV lamp and cylinder was $3 \mathrm{~mm}$ and the distance between the external lamps and cylinder outer surface was $5 \mathrm{~cm}$.

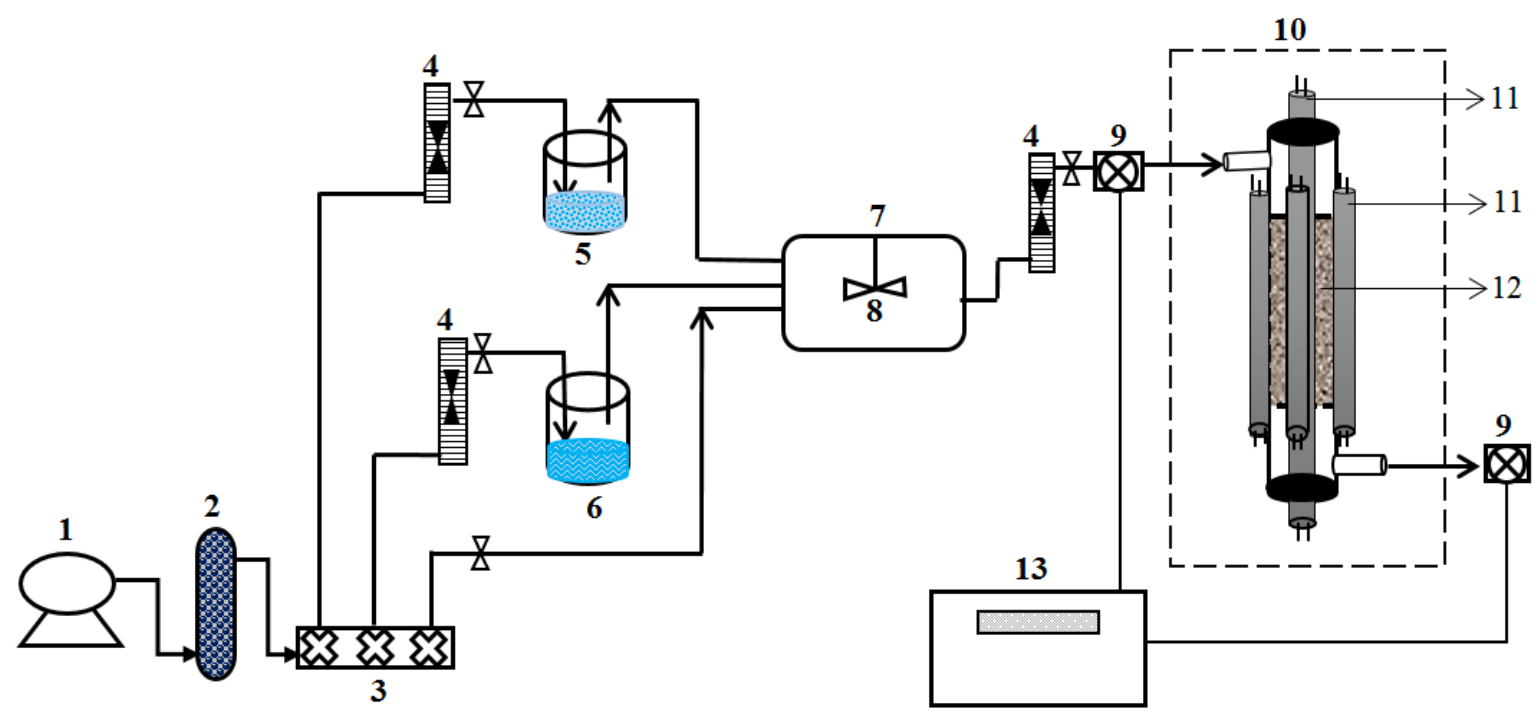

Figure 1: Schematic diagram of continuous flow reactor for photocatalysis. 1) Air pump; 2) Air cleaner; 3) Branch wall boxes; 4) Rotameter; 5) Styrene container; 6) Water container; 7) Mixing tank; 8) Electric fan; 9) Sampling port; 10) Photocatalytic reactor; 11) Ultraviolet (UV) lamps; 12) Catalyst; 13) Analyzer

The concentration of styrene in the output of equalizer chamber at 5-minute intervals was measured and recorded by direct reading of Phocheck Tiger (5000, Ion Science Inc, UK) which works with photoionization detector (PID) method. In order to ensure the reliability of obtained data, each of the measurements was repeated at least three times. To ensure the accuracy of the measured data, some of the concentrations were re-measured by gas chromatography (GC) (Philips Unicam, PU 4410, Netherlands) equipped with flame 
ionization detector (FID) which showed no significant difference.

STOE-STADV device (Japan) was used to record X-ray powder diffraction (XRD) pattern and to ensure the formation of ZSM-5 and $\mathrm{ZnO}$ zeolite phase. The wavelength of the device with $40 \mathrm{kV}$ and $40 \mathrm{~mA}$ generator was $1.54 \AA$. Zeolite samples were scanned at $2 \theta$ between $1^{\circ}$ to $80^{\circ}$. Quantachrome ChemBET was used to investigate the adsorptiondesorption isotherm of $\mathrm{N} 2$, to determine the specific surface area and pore size. In this method, the specific adsorption level was calculated by measuring the pressure of nitrogen gas injected into the objects. Evaluation of products morphology and estimation of particle size was done by SEM microscope (Hitachi S3500, Hitachi, UK) with the accelerating voltage of $15 \mathrm{kV}$.

To locate $\mathrm{ZnO}$ nanoparticles on the ZSM-5, with the weight percent (wt $\%$ ) of $5 \%$, a certain mass of $\mathrm{ZnO}$ was weighted by laboratory scale (accuracy of ten thousand) and poured into the erlen. Then, it was placed on ultrasonic devices for 30 minutes to create a uniform suspension. In the next step, a certain mass of zeolite was added to a suspension containing nanoparticles before putting it in a shaker for 12 hours continuously in order to get a complete mixture and have the $\mathrm{ZnO}$ nanoparticles stabilized on the surface and pores of zeolite. The resulted mixture was filtered by filter paper and dried at $80{ }^{\circ} \mathrm{C}$. For calcination, it was placed in the oven for 2 hours at $450{ }^{\circ} \mathrm{C}$.

\section{Results}

Figure 2 shows the XRD pattern of ZSM-5 and $5 \% \mathrm{ZSM}-5 / \mathrm{ZnO}$. The long and narrow peaks in both of beds indicate the presence of appropriate crystals. The results showed that the increased lines at $2 \theta=31.86$ and $2 \theta=$ 36.30 were related to the presence of $\mathrm{ZnO}$, reflecting the successful production of ZSM$5 / \mathrm{ZnO}$ photocatalyst.

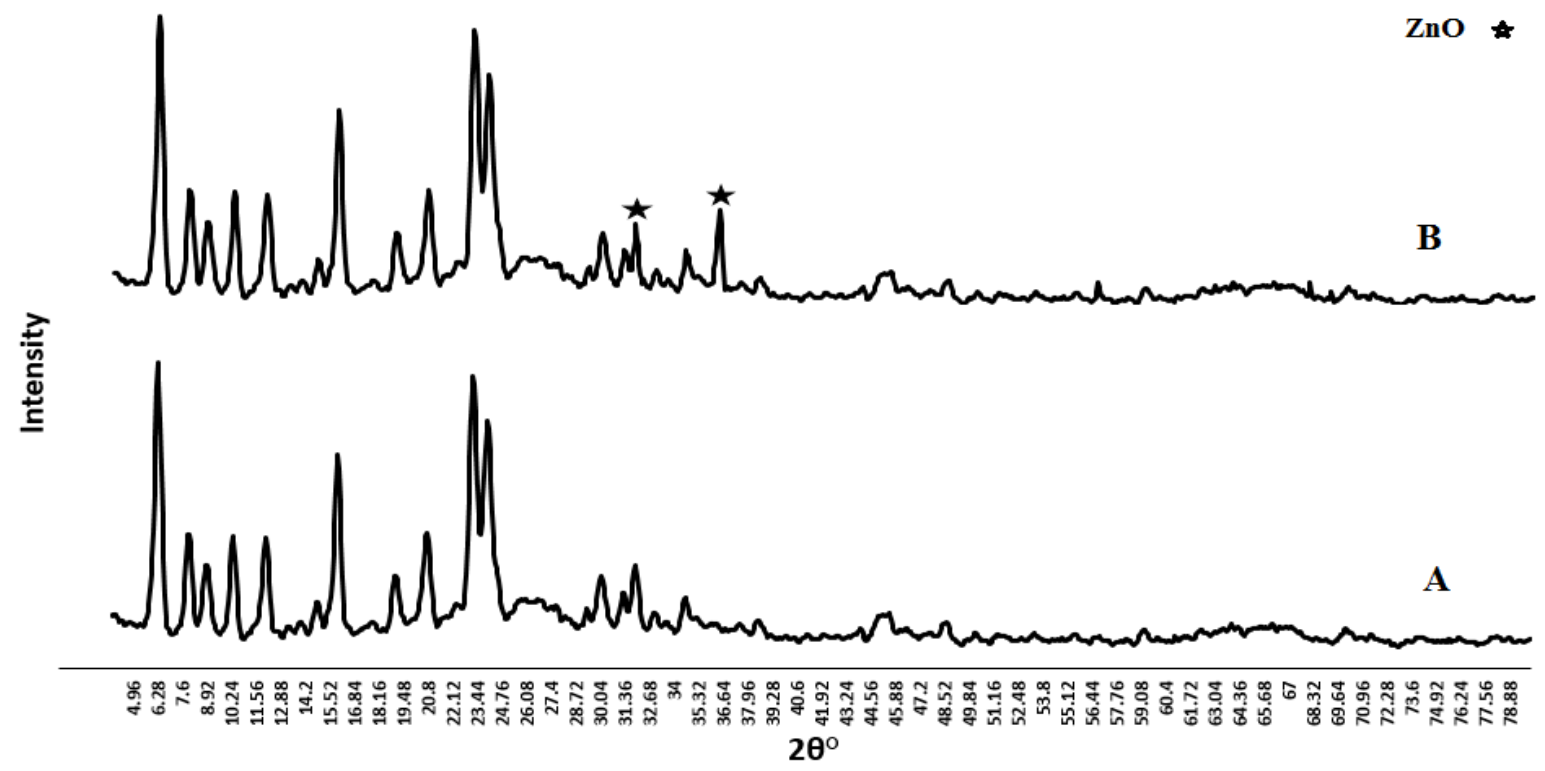

Figure 2: X-ray powder diffraction (XRD) pattern of A) ZSM-5 bed; B) ZSM-5/ZnO

The results from BET and Barrett-JoynerHalenda (BJH) tests showed that the ZSM-5 bed had a surface area of $356.4 \mathrm{~m}^{2} / \mathrm{g}$, indicating that the porosity of zeolite and average pore diameter was $0.25 \mathrm{~nm}$. According to the results, a total pore volume of zeolite in the unit of mass was $0.090 \mathrm{~cm}^{3} / \mathrm{g}$. After calcination and stabilization of nanoparticles of $\mathrm{ZnO}$ on the zeolite, its specific surface area and total pore volume decreased to $337.201 \mathrm{~m}^{2} / \mathrm{g}$ and $0.084 \mathrm{~cm}^{3} / \mathrm{g}$, respectively. The photocatalyst average pore 
diameter was $3.19 \mathrm{~nm}$, which indicated that

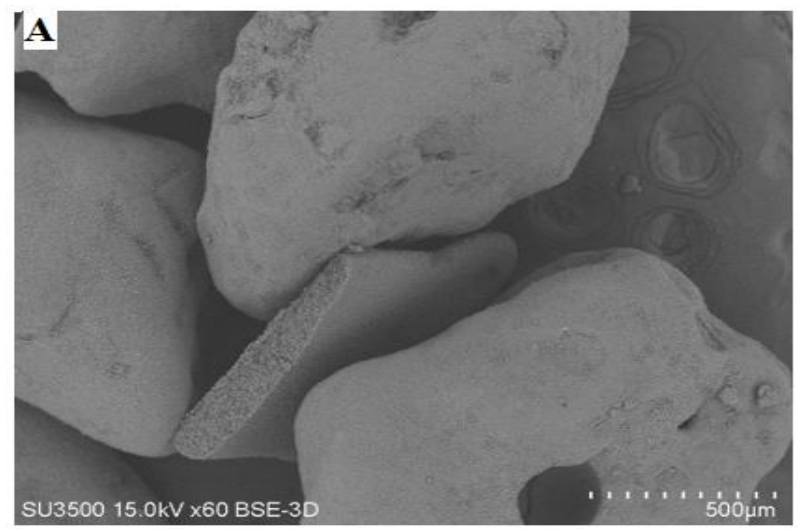

produced photocatalyst was nano-porous.

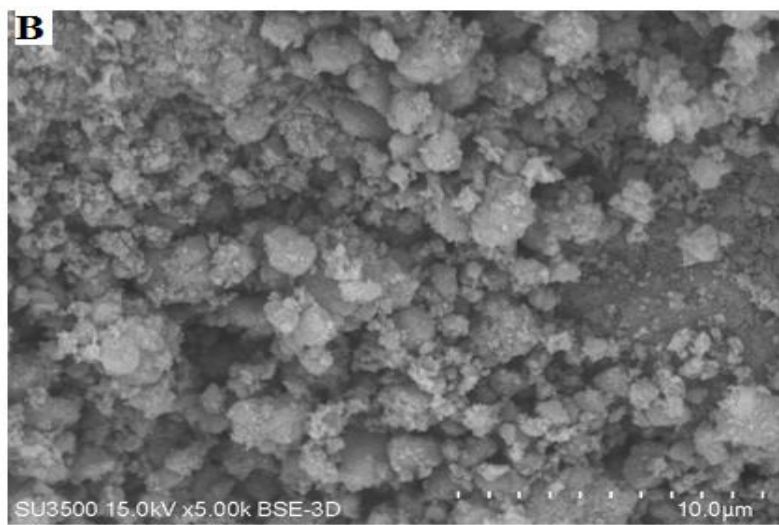

Figure 3: Scanning electron microscope (SEM) images. A) Zeolite Socony Mobil-5 (ZSM-5); B) ZSM-5/zinc oxide $(\mathrm{ZnO})$

The images obtained from ZSM-5 and ZSM$5 / \mathrm{ZnO}$ bed is shown in figure 3 . According to the SEM image of the $\mathrm{ZSM}-5 / \mathrm{ZnO}$ bed, $\mathrm{ZnO}$ particles were dispersed uniformly on the zeolite, demonstrating the successful stabilization of nanoparticles on the ZSM-5. In this study, $5 \% \mathrm{ZnO}$ was coated on the zeolite. In order to investigate the effect of UV on photocatalyst adsorption and removal process, the styrene vapor reduction in ZSM-5 bed was compared with ZSM-5/ZnO bed in a concentration of $100 \mathrm{ppm}$ and flow rate of 1 $1 /$ minute. As indicated in figure 4 , when the UV lamp was off, the styrene vapor adsorption in ZSM-5 zeolite and ZSM-5 coated with ZnO nanoparticles was $98 \%$ in the first 60 and 50 minutes of the test, respectively, and reached zero in the $240^{\text {th }}$ minute. On the other hand, when the UV lamp was on, the reduction of styrene in the first 75 minutes of the test was $98 \%$, and after 230 minutes reached $22 \%$ at a constant rate and remained constantly on average $21 \%$ up to 360 minutes. According to the statistical test (paired t-test), the removal amount of photocatalyst adsorption and removal process had significant differences in concentration of $100 \mathrm{ppm}$ and flow rate of 1 1/minute. This suggests that UV lamp imposed its photo degeneration effect on the process and increased the effectiveness. The optimum conditions of styrene removal efficiency were in the concentration of $20 \mathrm{ppm}$. Differences in the input and output concentrations in the adsorption and removal process can be attributed to the photocatalytic degeneration.

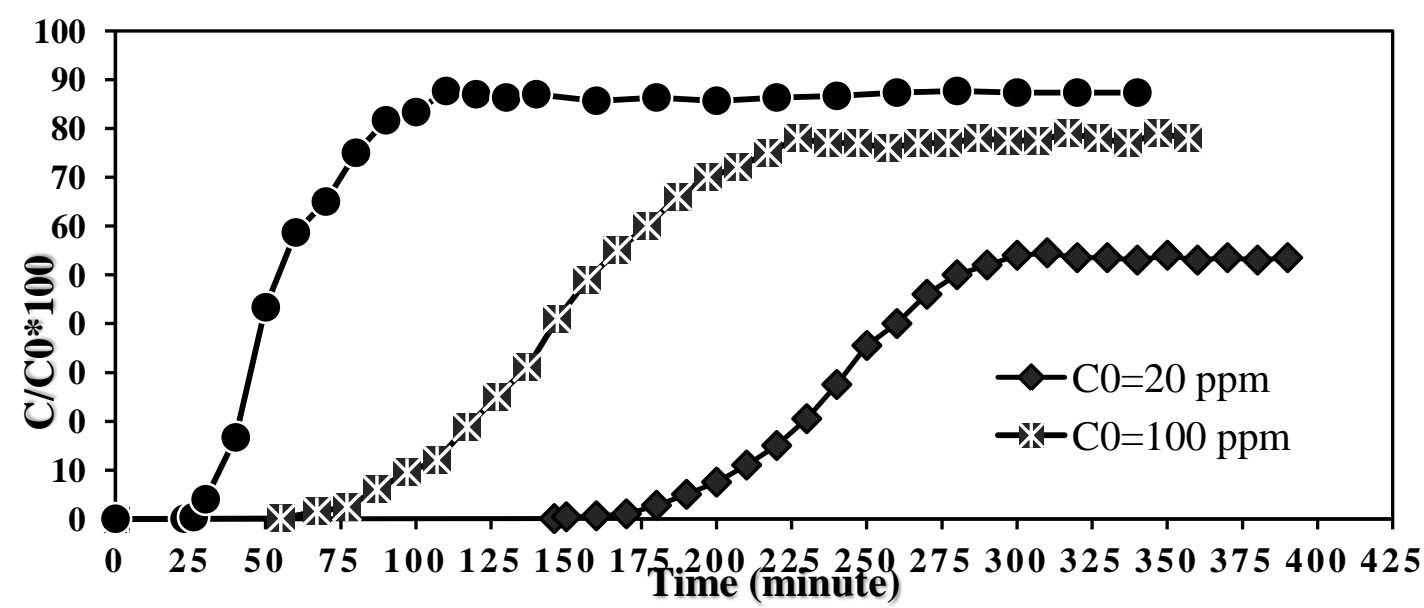

Figure 4: Adsorption and photocatalyst removal process. Concentration: 100 part per million (ppm), temperature: $25 \pm 1{ }^{\circ} \mathrm{C}$, bed amount: $2 \mathrm{~g}$, humidity: $35 \pm 1 \%$ 
Photocatalytic activity of reactor containing 2 $\mathrm{g}$ of $\mathrm{ZSM}-5 / \mathrm{ZnO}$ was examined by measuring the photocatalytic degradation of styrene in three different concentrations of $20 \mathrm{ppm}, 100$ ppm, and $300 \mathrm{ppm}$. As can be seen in figure 5, increasing in concentration resulted in a reduction of removal amount. Therefore, by increasing the concentration from $20 \mathrm{ppm}$ to $300 \mathrm{ppm}$, styrene removal efficiency decreased from $47.5 \%$ to $13 \%$ on average, showing the relatively good performance of the bed at low concentrations and its poor performance at high concentrations. The average removal rate of styrene in concentrations of $100 \mathrm{ppm}$ was $22 \%$. The results of this study showed that the adsorption and removal efficiency of styrene have been increased by stabilization of $\mathrm{ZnO}$ nanoparticles on the zeolite bed and the use of UV light.

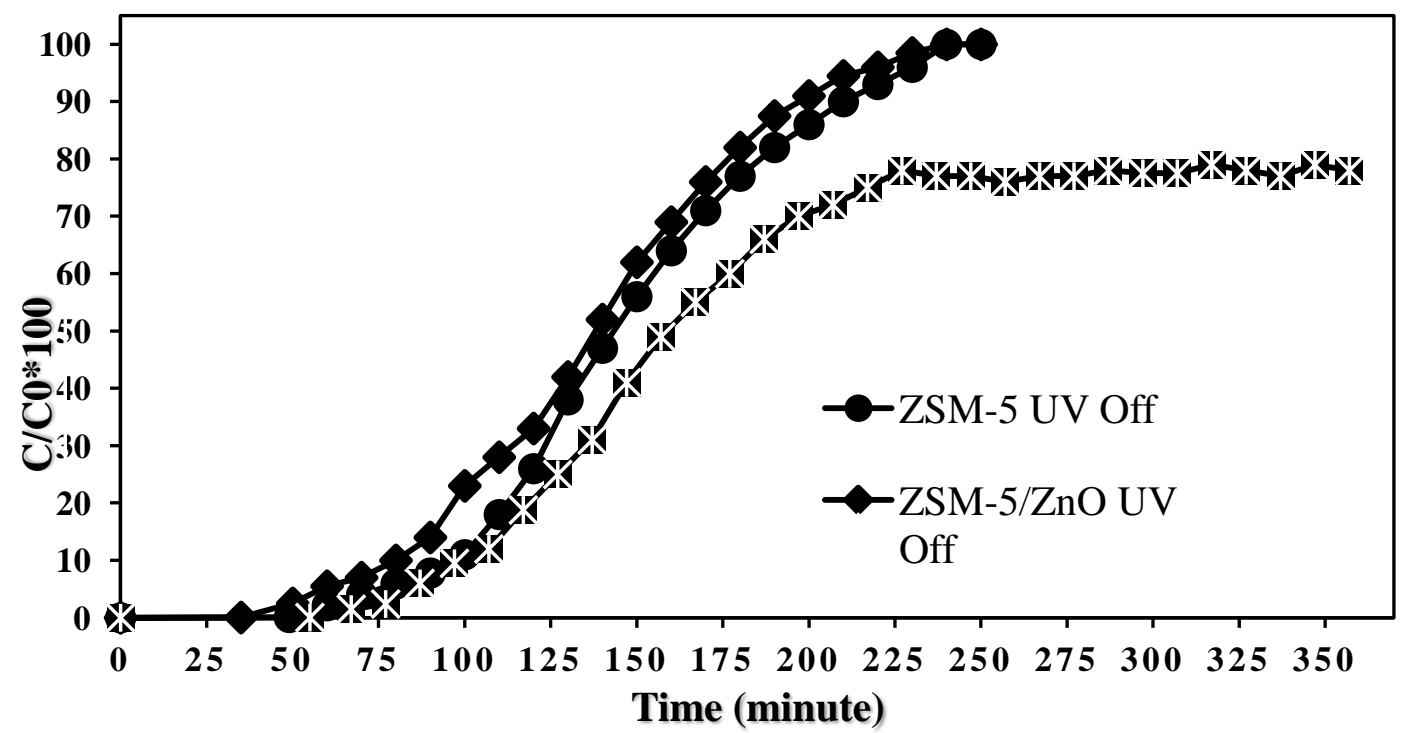

Figure 5: Photocatalytic removal of styrene. Temperature: $25 \pm 1{ }^{\circ} \mathrm{C}$, bed amount: $2 \mathrm{~g}$, humidity: $35 \pm 1 \%$ ZSM-5: Zeolite Socony Mobil-5; UV: Ultraviolet; ZnO: Zinc oxide

\section{Discussion}

In this study, $5 \% \mathrm{ZnO}$ was coated on the zeolite. The same weight ratio is achieved as the optimal amount in other researches conducted in this area. In a study by Chen et al. to remove trichloroethylene from the air by the $\mathrm{ZnO}$ /aluminum oxide (Al2O3) catalyst, the optimal wt $\%$ of active metal was achieved 5\% in the catalyst (22). Rostami et al. studied the optimal amount of copper oxide nanoparticles on the zeolite in the removal of benzene, toluene, and xylenes (BTX) compounds from the air and obtained $4.62 \%$ wt (23).

The results of this study showed that the adsorption and removal efficiency of styrene have been increased by stabilization of $\mathrm{ZnO}$ nanoparticles on the zeolite bed and the use of UV light. So, about $48 \%$ of pollutants in the reactor was removed at a concentration of 20 ppm. Mohamed et al. found that stabilization of $\mathrm{TiO}_{2}$ nanoparticles on the ZSM-5 zeolite could obtain high-efficiency degradation of EDTA (21). Differences in the input and output concentrations in the adsorption and removal process can be attributed to the photocatalytic degeneration. These results confirmed the results of Khatamiyan et al. study. Comparing the adsorption and removal of 4-nitrophenol from the aquatic environment using HZSM-5/ZnO nanocomposite (7\%), Khatamiyan et al. concluded that each of the processes of adsorption and removal alone cannot remove all contaminants and only in the case of a combination of these two processes, all the 4-nitrophenol are completely removed from the aquatic environment. They also reported that increasing the stabilization 
of $\mathrm{ZnO}$ (more than 7\%) on ZSM-5, reduces the amount of adsorption and removal (24).

In this study, the removal of styrene was investigated by $\mathrm{ZSM}-5 / \mathrm{ZnO}$ catalyst in two stages of on/off UV. As shown in figure 5, the use of UV light has greatly increased the removal efficiency in the $\mathrm{ZSM}-5 / \mathrm{ZnO}$ catalyst. UV radiation with energetic photons can dissociate oxygen and water into oxygen species and hydroxyl radicals $(\cdot \mathrm{OH})$, which are highly active for VOC oxidation (25).

The results of the styrene removal showed that by increasing the styrene concentrations the removal efficiency is reduced. Thus, it can be concluded that the lower removal rates at higher concentrations show a decline in the photodegradation response rate in higher concentrations. Many similar studies have achieved similar results by comparing the impact of the concentration on photocatalytic removal efficiency. For example, Rangkooy et al. in a study on photocatalytic removal of formaldehyde from air, using $\mathrm{ZnO}$ nanoparticles immobilized on bone char, suggest the same results (26). Studies have shown that with increasing concentration, a larger mass of styrene is removed from the air in a unit of time. Therefore, the breakthrough and saturated point adsorber are reduced (27, 28). On the other hand, by increasing the concentration in comparison to the number of molecules or the pollutants in comparison to the number of active places on the surface, the catalyst increases, and due to the increase in the speed of propagation and speed of penetration into the pores of the catalyst, absorption would occur faster. As a result, complete saturation of adsorption places on the surface of the catalyst occurs within a shorter time (29). Furthermore, the results of the current study showed that the rate of adsorption process enhanced by increasing the styrene concentration. The reason would be a large number of gas molecules that increase their possibility of transmission and connection with the adsorbent surface. That is why ZSM-5 zeolite has reached the point break earlier by increasing the styrene concentration at a constant flow rate. Asilian et al. studied the removal of styrene from the air by natural and modified zeolite, concluded that the concentration has a significant impact on adsorption (30).

\section{Conclusion}

Both of the adsorption and elimination mechanisms can affect contaminant removal efficiency in different conditions. In the case of ZSM-5 without nanoparticle, the dominant mechanism was adsorption. But in the presence of nanoparticles and UV light, the removal mechanism was dominant. It can be concluded from this study and similar studies that there is an optimal state compatible with the photocatalytic reaction conditions where, according to the amount of photocatalyst, UV radiation rate and intensity, temperature, humidity and other factors, the photocatalytic reaction reaches its maximum value. This optimum state depends on the type of adsorbent, so it should be examined for every situation. Further studies should be focused on designing experiments to be able to build a numerical model of conditions with a minimal number of samples, by obtaining detailed information about the light intensity, the amount of catalyst and other effective factors.

\section{Acknowledgments}

The authors deem necessary to express their gratitude to the professors of Occupational Health Engineering Department, Ahvaz Jundishapur, Iran, Tarbiat Modares University and Shahid Beheshti University, Tehran, Iran, for academic assistance to this article.

Conflict of interest: None declared

\section{References}

1- Adamson AW, Gast AP. Physical chemistry of surfaces. $6^{\text {th }}$ ed. Hoboken, New Jersey, United States: John Wiley \& Sons, Inc; 1997.

2- Hunter P, Oyama ST. Control of volatile organic compound emissions: Conventional and Emerging Technologies. $1^{\text {st }}$ ed. Hoboken, New Jersey, United States: John Wiley \& Sons, Inc; 2000 
3- Prieto-Castello MJ, Amorós DM, GarciaSagredo JM, Llorens AC. Evaluation of cytogenetic damage on workers exposed to low levels of styrene. Toxicol Lett 2011; 205(Supplement):S64.

4- Komarneni S, Esquivel S, Noh YD, Sitthisang $\mathrm{S}$, Tantirungrotechai $\mathrm{J}$, $\mathrm{Li} \mathrm{H}$, et al. Novel synthesis of nanophase anatase under conventional-and microwave-hydrothermal conditions: DeNOx properties. Ceram Int 2014; 40(1)Part B:2097-102.

5- Hashimoto K, Irie H, Fujishima A. TiO2 photocatalysis: a historical overview and future prospects. Jap J Appl Phys 2005; 44(12)Part 1:8269-85.

6- Fujishima A, Zhang X, Tryk DA. $\mathrm{TiO}_{2}$ photocatalysis and related surface phenomena. Surf Sci Rep 2008; 63(12):515-82.

7- Baruah S, Dutta J. Hydrothermal growth of $\mathrm{ZnO}$ nanostructures. Sci Technol Adv Mater 2009; 10(1):1-18.

8- Ehrentraut D, Sato H, Kagamitani Y, Sato H, Yoshikawa A, Fukuda T. Solvothermal growth of $\mathrm{ZnO}$. Progress in Crystal Growth and Characterization of Materials 2006; 52(4):280335.

9- Lizama C, Freer J, Baeza J, Mansilla HD. Optimized photodegradation of reactive blue 19 on $\mathrm{TiO}_{2}$ and $\mathrm{ZnO}$ suspensions. Catal Today 2002; 76(2-4):235-46.

10- Baruah S, Dutta J. Nanotechnology applications in pollution sensing and degradation in agriculture: a review. Environ Chem Lett 2009; 7(3):191-204.

11- Meléndrez MF, Hanks K, Leonard-Deepak F, Solis-Pomar F, Martinez-Guerra E, PérezTijerina E, et al. Growth of aligned $\mathrm{ZnO}$ nanorods on transparent electrodes by hybrid methods. J Mater Sci 2012; 47(4):2025-32.

12- Zhang Q, Dandeneau ChS, Zhou X, Cao G. $\mathrm{ZnO}$ nanostructures for dye-sensitized solar cells. Adv Mater 2009; 21(41):4087-108.

13- Shinagawa $T$, Watase $S$, Izaki M. Sizecontrollable growth of vertical $\mathrm{ZnO}$ nanorod arrays by a pd-catalyzed chemical solution process. Cryst Growth Des 2011; 11(12):55339.

14- Zhang J, Wang Sh, Xu M, Wang Y, Zhu B, Zhang Sh, et al. Hierarchically porous $\mathrm{ZnO}$ architectures for gas sensor application. Cryst Growth Des 2009; 9(8):3532-7.

15- Hong RY, Li JH, Chen LL, Liu DQ, Li HZ, Zheng Y, et al. Synthesis, surface modification and photocatalytic property of $\mathrm{ZnO}$ nanoparticles. Powder Technol 2009; 189(3):426-32.
16- Akin MB, Oner M. Photodegradation of methylene blue with sphere-like $\mathrm{ZnO}$ particles prepared via aqueous solution. Ceram Int 2013; 39(8):9759-62.

17- Nezamzadeh-Ejhieh A, Bahrami M. Investigation of the photocatalytic activity of supported $\mathrm{ZnO}-\mathrm{TiO} 2$ on clinoptilolite nanoparticles towards photodegradation of wastewater-contained phenol. Desalination Water Treat 2015; 55(4):1096-104.

18- Mumpton FA. Using zeolites in agriculture. In: Elfring $\mathrm{Ch}$, editor, Innovative biological technologies for lesser developed countriesWorkshop Proceedings. Washington DC, US: Office of Technology Assessment, OTA; 1985.

19- Kazemian H. Introduction to Zeolites, Misterious Minerals. Tehran: Behesht; 2005. P.124-8.

20- Wang H, Pinnavaia TJ. MFI zeolite with small and uniform intracrystal mesopores. Angew Chem Int Ed Engl 2006; 45(45):7603-6.

21- Mohamed RM, Ismail AA, Othman I, Ibrahim IA. Preparation of $\mathrm{TiO}_{2}-\mathrm{ZSM}-5$ zeolite for photodegradation of EDTA. J Mol Catal A Chem 2005; 238(1-2):151-7

22- Chen JCh, Tang ChT. Preparation and application of granular $\mathrm{ZnO} / \mathrm{Al}_{2} \mathrm{O}_{3}$ catalyst for the removal of hazardous trichloroethylene. $\mathrm{J}$ Hazard Mater 2007; 142(1-2):88-96.

23- Rostami R, Jonidi Jafari A, Rezaee Kalantari R, Gholami M. Survey of modified clinoptilolite zeolite and cooper oxide nanoparticles-containing modified clinoptilolite efficiency for polluted air BTX removal. Iranian Journal of Health and Environment 2012; 5(1):1-8.

24- Khatamian M, Alaji Z. Efficient adsorptionphotodegradation of 4-nitrophenol in aqueous solution by using ZnO/HZSM-5 nanocomposites. Desalination 2012; 286:24853.

25- Jeong J, Sekiguchi K, Lee W, Sakamoto K. Photodegradation of gaseous volatile organic compounds (VOCs) using $\mathrm{TiO}_{2}$ photoirradiated by an ozone-producing UV lamp: decomposition characteristics, identification of by-products and water-soluble organic intermediates. J Photochem Photobiol A Chem 2005; 169(3):279-87

26- Rangkooy H-A, Rezaee A, Khavanin A, Jafari AJ, JonidiJafari A, Khoopaie A-R. A Study on photocatalytic removal of formaldehyde from air using $\mathrm{ZnO}$ nanoparticles immobilized on bone char. Qom University of Medical Sciences Journal 2013; 7(2):17-26.

27- Mo J, Zhang Y, Xu Q, Lamson JJ, Zhao R. Photocatalytic purification of volatile organic 
compounds in indoor air: a literature review. Atmos Environ 2009; 43(14):2229-46.

28- Mishra T, Mohapatra P, Parida KM. Synthesis, characterisation and catalytic evaluation of iron-manganese mixed oxide pillared clay for VOC decomposition reaction. Appl Catal B 2008; 79(3):279-85.

29- Rezaei E, Soltan J, Chen N. Catalytic oxidation of toluene by ozone over alumina supported manganese oxides: Effect of catalyst loading. Appl Catal B 2013; 136-137:239-47.

30- Asilian H, Khavanin A, Afzali M, Dehestani S, Soleimanion A. Removal of styrene from air by natural and modified zeolite. Health Scope 2012; 1(1):7-11. 